\title{
IS Design Thinking in Disaster Management Research
}

\author{
Guido Schryen \\ University of Regensburg \\ guido.schryen@wiwi.uni-regensburg.de
}

\author{
Felix Wex \\ University of Freiburg \\ felix.wex@is.uni-freiburg.de
}

\begin{abstract}
Disasters caused by natural hazards continue to threaten millions of humans and various infrastructure capabilities each year. In their efforts to address disasters, aid organizations, national authorities and researchers have acknowledged that natural disaster management (NDM) poses diverse and immense challenges that are different from those in the management of most daily life situations. NDM has been addressed in different disciplines, including management science, operations research, the social sciences, and information systems. Having reviewed large parts of the literature, we identified a strong focus on either descriptive or explanatory research, and on the construction and evaluation of prototypic artifacts. However, what NDM research widely lacks is generic and abstract design knowledge. Such contributions are recognized in IS design science (ISDS) research as design principles and design theories. Given the experience of ISDS research to produce high-level design knowledge, we derive implications for future research in a key area of NDM.
\end{abstract}

\section{Introduction}

Disasters caused by natural hazards, including earthquakes, tsunamis, hurricanes and floods, continue to threaten millions of humans and various infrastructure capabilities each year. The 2010 earthquakes in Haiti and Chile, the 2004 Indian Ocean tsunami, and the recent earthquake and tsunami in Japan show the massively destructive power of natural disasters in the recent past.

In their efforts to take precautions before disasters, to react during disasters, and to perform recovery actions after disasters, aid organizations, national authorities and researchers have acknowledged that natural disaster management (NDM) poses diverse challenges that are different from those arising in the management of most daily life situations [8].

The management of natural disasters shows severe deficiencies. As Day et al. [10] note, despite attempts by organizations and governmental authorities, response and recovery efforts are often inefficient. This is not surprising, given the huge communication, coordination and decision challenges in NDM. It turns out that many of these challenges are strongly related to design issues, regarding both communication and decision processes, and information and communication system building. Interestingly, though there are many scholar and practitioner papers on disaster management and though there is a huge potential to manage coordination in NDM with information systems, there is a lacuna of literature discussing how to design information systems [9]. Beyond the design of information systems, we see an even bigger potential of IS design science to help inform and address critical aspects in NDM: NDM needs to consider a bundle of different types of objects, including persons, organizations, processes, and technologies. This requirement is very well matched by the problem space of IS design science, which uses persons, structures, technologies, and working systems [23]. As Gregor and Jones [18] remark, a particular characteristic that distinguishes IS from other fields is the concern to use artifacts in human-machine systems. Thus, we argue that ISDS cannot only contribute to developing information system artifacts, but it can also inform other NDM areas, including early warning, disaster prediction, standardization, coordination, monitoring, and data analysis.

The objective of our research perspective therefore, is to show how IS design principles and design thinking can apply to NDM, which is increasingly concerned with design but is yet unfamiliar with design thinking. The remainder of this paper is structured as follows: In Section 2, we introduce NDM research and elaborate its challenges. Section 3 presents an introduction into IS design science research and shows its artifacts and methodologies. In Section 4, we briefly present the results of our literature review. Section 5 exemplifies how IS design thinking can be applied to NDM by focusing on resource coordination decision making. Finally, we conclude our research perspective. 


\section{Disaster management research}

Events that have a massively negative large-scale impact on people have been inconsistently named "emergency", "hazard", "catastrophe", "incident", "disaster", and "crisis" in the literature. Being consistent with the terminology of the International Federation of Red Cross and Red Crescent Societies (IFRC) [27] and the U.S. Federal Emergency Management Agency (FEMA) [13], we use the term "disaster" in the following sense (IFRC): "A disaster is a sudden, calamitous event that seriously disrupts the functioning of a community or society and causes human, material, and economic or environmental losses that exceed the community's or society's ability to cope using its own resources." [27] The types of events that are covered by the IFRC disaster definition are broad and include natural, manmade, and technological disasters. In this paper, we focus on natural disasters.

The management of natural disasters (NDM) poses diverse and immense challenges that are different from those arising in the management of most daily life situations. In particular, NDM has to cope with high uncertainty, sudden and unexpected events, increased time pressure, large-scale impact and damage, severe resource shortage, high demand for timely information in the presence of the disruption of infrastructure support and chaos [8]. The complexity of NDM is further enhanced through the involvement of several organizations across different cultural, national, and jurisdictional boundaries, at various administrative levels [4] and with their own systems and services. The particular importance of NDM is reflected in many journals, research centers, organizations and agencies, guides and directories, and news sources [3]. There is consensus in the literature that challenges and activities of disaster management can be classified along the preparedness phase, the response phase, and the recovery phase [8]. Table 1 lists challenges and activities of these phases.

\section{IS design science thinking}

\subsection{Introduction and origin}

The idea to distinguish what we call "design sciences" from other types of sciences was inspired by the seminal work of Simon [55], who created the term "science of the artificial". The creation of design sciences has led to a widely accepted classification of today's scientific disciplines into three categories: formal (philosophy, mathematics), explanatory (natural sciences and major sections of the social sciences) and
Table 1. Challenges and activities in NDM

\begin{tabular}{|l|l|}
\hline Phase & Challenge \\
\hline \multirow{5}{*}{ Preps } & Early warning [58] \\
\cline { 2 - 3 } & Disaster prediction [56] \\
\cline { 2 - 3 } & $\begin{array}{l}\text { Simulation and training for emergency } \\
\text { control centers [4] }\end{array}$ \\
\cline { 2 - 3 } & $\begin{array}{l}\text { Standardization of data formats, } \\
\text { contents, and protocols for cooperation } \\
\text { and communication [57] }\end{array}$ \\
\cline { 2 - 3 } & $\begin{array}{l}\text { Information supply for aid } \\
\text { organizations [24; 34] }\end{array}$ \\
\cline { 2 - 3 } Response & Evacuation planning [40] \\
\cline { 2 - 3 } & $\begin{array}{l}\text { Real-time information supply [10; 24] } \\
\text { scheduling of resources [51] }\end{array}$ \\
\cline { 2 - 3 } & $\begin{array}{l}\text { Activity recording and tracing of } \\
\text { rescue and response [34] }\end{array}$ \\
\cline { 2 - 3 } Navigation for search and rescue [32] \\
\hline Recovery & $\begin{array}{l}\text { Person finding (Google's web-based } \\
\text { person finder) }\end{array}$ \\
\cline { 2 - 2 } & $\begin{array}{l}\text { Data analysis for } \\
\text { improvements and controlling [15] }\end{array}$ \\
\hline
\end{tabular}

design sciences research (engineering, medical science, and modern psychotherapy) [59]. Formal science research is normative, based on axioms and logical rules, and strives for deduction. While in explanatory sciences the research object is an explanandum [61], in design sciences it is the mutandum [61] and the outcome is the "technological rule", which is "an instruction to perform a finite number of acts in a given order and with a given aim" [7, p. 132]. Van Aken, [59; p. 224] notes that "[t] he mission of design science is to develop knowledge for the design and realization of artefacts, i.e. to solve construction problems, or to be used in the improvement of the performance of existing entities, i.e. to solve improvement problems." Thus, prescription-driven research based on the paradigm of the design-sciences is utility-oriented.

\subsection{Artifacts and methodologies}

In order to get a clear understanding of how ISDS thinking can contribute to solving serious challenges in NDM research, we regard it essential to provide a concise picture of the "key ingredients" or "building blocks" of ISDS. We find the conceptualization of Gregor and Hevner [19] useful, who distinguish three ingredients: (1) the nature of the artifacts/problems studied (object), (2) the research approaches used (methodology), and (3) the nature of the artifacts produced (contribution). The term "artifact" is substantial in design science thinking. Based on [55], 
Gregor and Jones [18, p. 313] provide a useful description by defining an "artifact" as "something that is artificial, or constructed by humans, as opposed to something that occurs naturally."

While Iacono and Orlikowski [44] adopt a technical focus on studied artifacts, Hevner et al. [23] favor a more expansive view of IS, which includes people, organizations and their existing or planned technologies. We concur with the latter understanding. Regarding methodologies used in ISDS, [55;41] argue in favor of a multi-methodological approach, including analytical simulations, systems development, computational methods, and empirical methods. Sein et al. [53, p. 38] argue that " [...] traditional design science does not fully recognize the role of organizational context in shaping the design as well as shaping the deployed artifact", and they suggest "action design research" as a new design research method. Approaches to structure methodologies can be found in $[35 ; 48]$, who suggest two design processes (build and evaluate), and in $[31 ; 46]$, who present a generic ISDS research methodology. With regard to the latter contribution, there still seems to be partial disagreement in the literature, or at least two ISDS research communities, as [19] note: the "design theory camp" and the "pragmatic design camp". While the former, exemplified by $[62 ; 36 ; 18]$, requires a design theory as the basis for the building of a design artifact, the latter, exemplified by $[8 ; 2835 ; 41]$, is reported to be seen as agnostic to the need for design theory. Gregor and Hevner [19; p.4] argue that these views are not contradicting, but complementary with different presentation foci. We also argue that these views are not contradicting, but for a different reason: A closer look at the various references reveals that a substantial root of misunderstanding and camp building is the inconsistent use of terms, including "models" and "theories". Our argument is consistent with the observation in [31]. We further argue that these two camps are not appropriate for structuring the ISDS literature or for guiding future ISDS research activities. We rather promote the idea of distinguishing material artifacts (instantiations) from abstract artifacts (models, frameworks, theories) as proposed in [18].

We now have a closer look at the literature in order to justify our perspective. We first address references that are subsumed by Gregor and Hevner [19] to the "pragmatic design camp", we then proceed to the "design theory camp".

3.2.1. Pragmatic design camp. March and Smith [35; p. 256ff] classify output artifacts in four groups: constructs, which form the vocabulary of a domain; models, which are a set of propositions or statements expressing relationships between constructs; methods, which are sets of steps used to perform a task and which are based on constructs and models; and instantiations, which realize artifacts in particular environments and which operationalize constructs, models and methods. The authors seem to explicitly exclude theories by saying "Building and evaluating IT artifacts have design science intent. Theorizing and justifying have natural science intent." (p. 256) However, they have a narrow understanding of theories: "The theories must explain how and why IT systems work within their operating environments." (p. 255) Their perspective includes explanatory theories only, but theories do not necessarily need to contain explanatory components [17].

Nunamaker [41; p. 94] says: "Theory building includes development of new ideas and concepts, and construction of conceptual frameworks, new methods, or models (e.g., mathematical models, simulation models, and data models). Theories (particularly mathematical models) are usually concerned with generic system behaviors and are subjected to rigorous analysis." This paragraph clearly reveals that the authors do not sharply distinguish "theory" and "model". The authors do not explicitly consider explanatory components.

Iivari [28] distinguishes descriptive knowledge (that strives for truth value) and prescriptive knowledge (that does not strive for truth value), which includes design product knowledge, design process knowledge and technical norms. Artifacts include idea, concept, style, functionality, behavior, architecture, structure, and possible instantiation, but no explanatory components. The authors also seem to argue that theories have explanatory character: "To me, artifacts, if theories are excluded, do not have any truth value, and theories that describe and explain reality outside our mind have truth as correspondence [...].”[28,p. 45]

If we compare and summarize the aforementioned understandings of ISDS artifacts, we conclude that a) no universally agreed understanding (and distinction) of models, frameworks, theories exist (with the exception of [35]), and b) theories are assumed to have explanatory content included and are thus excluded from the list of potential ISDS contributions. The referenced papers do not consider theories other than explanatory theories, such as theories for analysis, prediction, or design and action [17].

3.2.2. Design theory camp. Consistent with the perspective of [17], the existence of various theories in the IS discipline is acknowledged in [62]. The authors suggest that an ISDS theory includes two aspects, one that deals with the product and another one that deals with the process of design. They also provide a comprehensive definition of an IS design theory ( $p$. 
42f). This definition excludes explanatory components, as "a design theory can never involve pure explanation or prediction" (p. 41).

Extending the understanding of [62] and drawing on the seminal works of [11;39], Gregor and Jones [18] provide a skeleton of an IS design theory that includes constructs, propositions, and justificatory knowledge, among others. The authors argue: "We would argue [...] that 'constructs, models and methods' are all one type of thing and can be equated to theory or components of theory, while instantiations are a different type of thing altogether." (p. 320). Consistent with [17], they classify an IS design theory as "theory for design and action". In principle, they distinguish two types of ISDS artifacts: a) instantiations or material artifacts, b) theories or abstract artifacts.

As [18; p.313] note, theories for design and action continue to be influential in IS, although they are not always recognized as theories. Seminal examples are "Emergent Knowledge Processes Design Theory" [36], and "ISDT for Learning-Oriented Knowledge Management Systems" [21].

3.2.3. Conclusions. Matching the understandings of the alleged two ISDS camps reveals that (1) there is agreement that ISDS artifacts should not contain explanatory elements, (2) the alleged contradiction of understandings of whether ISDS artifacts contain ISDS theories or not can be resolved through thorough definitions of key terms, including "model", "framework", "theory", (3) the ISDS discipline has not created a well-accepted definition of these terms, and (4) ISDS artifacts comprise two types of artifacts: material artifacts/instantiations and abstract artifacts. As a consequence of these results, we conclude that a classification of ISDS artifacts according to (4) is a useful approach for our further proceeding, rather than adopting more fine-grained classifications, such as the three-level classification of [19], which may lack consensus in the ISDS community.

\section{Scholarly contributions to disaster management}

NDM has been addressed by scholars of different disciplines, including management science, operations research, the social sciences, computer science, medicine, geophysics, forensic science, oceanography, meteorology, biology, psychology, and information systems. This multidisciplinary coverage is not surprising, given the diverse requirements of NDM. At it is far beyond this article to provide a comprehensive literature review of all these disciplines, we cover contributions of the IS discipline community only, with a focus on design-oriented papers.

Our literature search reveals that the IS discipline addressed disaster management as early as in the 1980 s; for a good overview of early works see [20]. While only a few of the identified papers are of descriptive nature, the majority of research contributions is design-oriented. Some of the designoriented papers cover more than one phase of NDM: Frameworks are suggested in [8], who develop a framework to analyze coordination patterns occurring in the emergency response life cycle. The provision of models can be found in [22], who propose knowledgebased models for emergency management systems. [33] contribute design principles for information processing and communication.

The majority of design-oriented IS papers on NDM can be assigned to one of the key phases of NDM, namely the preparedness phase, the response phase, and the recovery phase. We structure the presentation of the IS literature papers along these phases and unfold their key design science elements, namely the artifacts/problems/objects studied, the research methodology used, and the research artifact. Table 2 summarizes the results.

In the preparedness phase, the focus of studied problems is on coordination, evacuation planning and communication technology, information networks, prediction, and the forecast of insured losses. Drawing on discrete-event modeling, agent-based modeling, simulation, and risk management methodology, some abstract artifacts have been proposed in terms of a simulation model architecture, a model for pre-disaster preparation, a data-analytical forecasting model, a framework for systems and the design of evacuation support system, and also some material artifacts have been developed in terms of prototypes of an information network system, a virtual emergency operations center for disaster management and training, and a spatial decision-support system.

The response phase has attracted the highest level of attention. Studied problems include processes related to improvisation, scheduling and allocation, decision making, coordination, communication and collaboration, information management, and knowledge elicitation. From a system perspective, critical incident response systems, emergency response information systems, real-time decision support systems, communication systems, and information management systems belong to the mostly analyzed objects. Researchers have drawn on a wide spectrum of methodologies, including operational risk management, interviews, advance structuring and dynamic adjustment, coordination theory, combinatorial auction methods, grounded theory, case 
Table 2. ISDS papers in natural disaster management research

\begin{tabular}{|c|c|c|c|}
\hline Ref. & Artifacts studied & Research methodology & Research artifact \\
\hline \multicolumn{4}{|c|}{ Preparedness } \\
\hline$[16]$ & Coordination & Discrete-event modeling & Simulation model architecture \\
\hline$[52]$ & Information network & -- & Model for pre-disaster preparation, prototype \\
\hline [4] & Coordination & -- & Virtual Emergency Operations Center \\
\hline [40] & Evacuation planning & Simulation & Spatial decision-support system \\
\hline [54] & Wildfire prediction & -- & Prototype of an execution information system \\
\hline [26] & Forecast of losses & Risk Management & Data-analytical forecasting model \\
\hline [38] & Improvisation & Risk management & Concept of decision support \\
\hline \multicolumn{4}{|c|}{ Response } \\
\hline$[51]$ & $\begin{array}{l}\text { Scheduling and } \\
\text { assignment of resources }\end{array}$ & Meta heuristics & Decision support system (conceptual) \\
\hline [60] & Crisis decision making & -- & Mental models \\
\hline [9] & $\begin{array}{l}\text { Incident response } \\
\text { systems }\end{array}$ & $\begin{array}{l}\text { Emergency management } \\
\text { concepts; Interviews }\end{array}$ & Design principles \\
\hline [57] & $\begin{array}{l}\text { Emergency response } \\
\text { information systems }\end{array}$ & Literature review & $\begin{array}{l}\text { Framework for system design and development; } \\
\text { General and supporting design principles }\end{array}$ \\
\hline [5] & Information management & Coordination theory & Inform. mngmt. roles and dynamic capabilities \\
\hline [3] & Reallocation of resources & Combinatorial auctions & Cost framework \\
\hline$[10]$ & Information flows & $\begin{array}{l}\text { Grounded theory; } \\
\text { casestudy }\end{array}$ & Design principles \\
\hline [6] & Information provision & -- & GIS based information and DMSS \\
\hline [20] & Communication systems & Exploratory case study & Architecture for crisis response systems \\
\hline [14] & Comm./collaboration & Extreme Programming & Prototype of an emergency response system \\
\hline [30] & Decision making & -- & Framework for DSS \\
\hline$[12]$ & Decision making & Field study & Decision Support Framework \\
\hline [22] & Information flows & -- & Knowledge Model Architecture \\
\hline [47] & $\begin{array}{l}\text { Trends in information } \\
\text { management systems }\end{array}$ & $\begin{array}{l}\text { Literature review, historic } \\
\text { experience }\end{array}$ & $\begin{array}{l}\text { Logic and integration of incident management } \\
\text { systems }\end{array}$ \\
\hline [29] & $\begin{array}{l}\text { Information supply and } \\
\text { stable communication }\end{array}$ & $\begin{array}{l}\text { Analysis of former } \\
\text { crashes, ER modeling }\end{array}$ & $\begin{array}{l}\text { Components and dependencies in information } \\
\text { systems for earthquake disasters }\end{array}$ \\
\hline [37] & Knowledge elicitation & Questionnaire/experiment & Algorithm to aggregate knowledge \\
\hline$[50]$ & Task assignment & Simulations & Allocation mechanisms \\
\hline$[52]$ & Information network & -- & Prototype of Information Network system \\
\hline \multicolumn{4}{|c|}{ Recovery } \\
\hline$[52]$ & Information network & -- & Prototype of Information Network system \\
\hline
\end{tabular}


study, field studies, and workflow management. Contributions have been similarly diverse, comprising frameworks and models for decision (support systems) and system design and development, design principles, knowledge model architectures, components and dependencies in information systems, algorithms to aggregate architecture for crisis response systems, knowledge and graphical representation, and allocation mechanisms. Prototypes have been developed primarily for decision support systems. Interestingly, the recovery phase has been neglected in the literature. We found only one reference [52].

\section{Applying IS design thinking to resource coordination decision making}

The previous sections reveal that ISDS research has started to provide valuable contributions to various issues of the NDM domain. However, we argue that ISDS thinking has not tapped its full potential to support researchers in solving NDM issues. We rather argue that the rich set of methodologies, models, and theories in ISDS research can inform NDM research more substantially than it is actually the case. We illustrate the ISDS potential by focusing a particular problem in NDM research, the decision support regarding the coordination of (the allocation and scheduling of) resources during the response phase [51]. We draw on the "IS Design-Science Research Guidelines" suggested by Hevner at al. [23] in order to provide examples of how these have been or might be applied in this decision support area.

During a disaster, a major challenge is the coordination of the various resources (personnel, material) that are distributed over many aid organizations and their teams [51]. Coordination issues are extremely time-critical as casualties need to be rescued during the first 72 hours, and they are regarded as key issues during disaster response $[3,8]$. The design of support systems for coordination requires knowledge on when to apply centralized or distributed coordination, how to design appropriate coordination systems, and which algorithms to use. The IS (and the Operations Research) literature has started to address this issue; for example, decision support artifacts are suggested by $[3 ; 12 ; 30 ; 38 ; 57]$, information management roles and dynamic capabilities for disaster management are suggested in [5], and algorithmic support is provided in [50;51]. However, the results of these works show two shortcomings: 1) They focus mainly on instantiations rather than on theories or abstract artifacts (for a discussion of these concepts, see Subsection 3.2). 2) They do not account for decision support challenges that are different from those in a "regular" business context: the high level of data uncertainty, increased decision time pressure, severe resource shortage, and the high demand for timely information in the presence of the disruption of infrastructure support and chaos [8]. Also the complexity of the coordination of resources is further increased through the involvement of several organizations with their own systems and services [4].

Drawing on the ISDS guidelines of Hevner et al. [23], we now outline how ISDS thinking can help to address the aforementioned shortcomings.

\subsection{Design as an artifact}

While the importance and difficulty of providing decision support for the coordination of resources is acknowledged, the NDM literature is remarkably silent on how this task may be accomplished. We argue that both decision support processes and decision support systems in centralized and decentralized decision environments are key artifacts that should be focused in further NDM research. Principles of how such artifacts should be built (process of design) and how they should be structured (designed product) are well addressed in ISDS [36;62]. Based on the above decision support challenges, it is of particular importance to gain knowledge on how decision processes and systems should be built and used in order to account for timely decisions, scarce resources, and informational uncertainty. Interestingly, early ISDS research in the 1980s already started to contribute toward solving this issue: Housel et al. [25] suggest a "generic procedure for designing and implementing information systems for crisis management" and a "generic crisis support organization", and Nunamaker et al. [41] suggest a "model of a crisis management environment". More recent works suggest applying optimization models for the allocation and the scheduling of resources $[51 ; 63]$. However, these models are immature; for example, they do not account for informational uncertainty. Future design work needs to identify appropriate paradigms and models of uncertainty. In the absence of reliable historical data and the presence of linguistic uncertainty of human actors, fuzzy set theory and programming [64] might be a valuable way to deal with uncertainty.

\subsection{Problem relevance}

As stated above, the timely coordination of resources is a key challenge during emergency response as the first 72 hours are time-critical for saving lives. In order to speed up decision processes regarding the coordination of resources, in the presence 
of many aid organizations with their own information systems it is essential to establish efficient interorganizational decision processes and supporting decision support systems. However, it should be noted that in contrast to traditional business settings, where often the increase of revenue or the decrease of cost are the ultimate goals of design, in disaster response other goals (and dependent variables) are relevant: dependent variables are now casualties, damage, and speed of decision and rescue action.

\subsection{Design evaluation}

The evaluation of decision support processes and systems (for the coordination of resources) as design artifacts is a necessary activity in order to assess the artifacts in terms of depending variables (cmp. the Subsection on problem relevance), and to subsequently improve them. However, not all of the suggested design evaluation methods in [23] are applicable. For example, observational evaluation methods are inappropriate as case studies and field studies in realword disasters can have severe consequences for human lives when the artifacts show unexpected deficiencies. We rather suggest that interviews with authorities and aid organizations be conducted to study their decision behavior and coordination policies, and that optimization (analytical method) and simulation (experimental method) of decision support processes and systems be applied. The latter design evaluation methods have already been applied in $[51 ; 63]$.

\subsection{Research contributions}

Contributions of design science research are design artifacts, design construction knowledge (foundations), and/or design evaluation knowledge (methodologies) [23]. We see the potential of ISDS to provide all three types of contributions for the decision support of the coordination of resources. Regarding design artifacts, decision support processes and systems as necessary artifacts (cmp. the subsection "Design as an Artifact"). Design construction knowledge is ideally based on domain knowledge gained through interviews with aid organizations and authorities. This design construction knowledge can include, for example, models of decision processes, frameworks of decision support systems, and dependent variables as constructs. This design construction knowledge can in turn provide addition to the NDM knowledge base. Finally, the development and use of design evaluation methods as described in the previous subsection, including the definition of metrics for dependent variables, can inform the NDM domain. However, while in traditional business settings often only financial metrics are relevant, in disaster response settings dependent variables include casualties, financial harm, and speed of response. Metrics for these variables cannot be simply aggregated but should be regarded as multiple criteria. Thus, models and methods of multicriteria optimization can provide crucial components of design-science research in NDM.

\subsection{Research rigor}

The above discussion of artifacts and research contributions of the coordination of resources already showed the applicability of rigorous methods in both the construction and the evaluation of the designed artifacts. They include the construction of effective metrics for dependent variables, mathematical formalism in terms of optimization and simulation models, and also models for the representation of decision processes. Such processes can be modeled and evaluated, for example, formally by means of Petri nets, or semi-formally by means of UML diagrams. While Petri nets have a stronger mathematical background (rigor), UML diagrams are easier to understand and to use for practitioners (relevance). This example illustrates a trade-off between rigor and relevance, which is discussed also by Hevner et al. [23, p. $87 \mathrm{f}]$.

As the above discussion of challenges in the coordination of resources reveals, decision makers face diverse and immense challenges that are different from those in business management. It contains many problems that are ill-structured or "wicked". For such types of problems, Pries-Heje and Baskerville [48;49] propose a "design theory nexus", which "[...] is a set of constructs and methods that enable the construction of models that connect numerous design theories with alternative solutions. " [49, p. 731]

\subsection{Design as a search process}

The effectiveness of decision support artifacts needs to be assessed in terms of how well they support dependent variables (casualties, harm, etc.). This buildand-evaluate sequence need to be iterated in order to improve models and methodologies. In design science, this approach is referred to as "generate-test cycle" [55]. The cycle is useful in the design and evaluation of decision optimization models when due to computational complexity these models are solved with heuristics or Monte Carlo simulations, which do not guarantee to get optimal solutions. In such cases it is common to refine models and/or algorithms until it 
can be proven that a heuristic design solution is within close proximity of an optimal solution.

\subsection{Communication of research}

We agree with Hevner et al. [23] that design science research must be presented to both technologyoriented and management-oriented audiences. Following the suggestion to present details in concise, well-organized appendices, we suggest that architectures of decision support systems, models of decision support processes, optimization and simulation models, and algorithms are presented in appendices. UML diagrams, Petri-nets, pseudocode, and Nassi-Shneiderman diagrams are a few examples of well-established representation tools that are useful for presenting decision-oriented artifacts for the coordination of resources.

\section{Conclusions}

Natural disasters have hit and will continue hitting our societies, businesses, and economies [3]. NDM has been addressed by different disciplines, including the IS discipline. Having reviewed large parts of the literature, we identify a strong focus on either descriptive or explanatory research, or on the construction and evaluation of prototypic artifacts. Regarding the latter, we show that researchers have developed instantiations in terms of situated processes, systems, and algorithms, all of which are important design science artifacts. However, what NDM research widely lacks is generic, abstract, and more general design knowledge that is useful to construct effective processes, algorithms, and systems across a wide range of specific incident situations. Such contributions are recognized and addressed in IS design science (ISDS) research as design principles and design theories. Given the rich history and experience of ISDS research to produce such high-level design knowledge, we show for a particular problem in NDM research, the decision support regarding the coordination of resources during the response phase, how IS design thinking can inform NDM research.

We conclude our paper with two implications for a future research agenda "NDM meets ISDS": (1) NDM research can benefit from adopting ISDS knowledge on how to develop design principles and design theories. (2) ISDS should pay more attention on producing (high-level) NDM design artifacts. This domain has been neglected in ISDS so that there is still a huge need for knowledge on how to design IS for NDM. However, having seen that NDM challenges are multidisciplinary, we argue in favor of an IS design science discipline that does not draw the lines at design sciences of other disciplines. We rather argue in the sense of $[43 ; 46]$ that IS design science should also integrate and draw on the design sciences of other disciplines, such as operations research, management science, and computer science, which all have strong methodological backbones.

\section{References}

[1] Abbasi, A., and Chen, H. (2008). CyberGate: A Design Framework and System for Text Analysis of ComputerMediated Communication. MIS Quarterly, 32(4), 811-837.

[2] Adomavicius, G., Bockstedt, J. C., Gupta, A., and Kauffman, R. J. (2008). Making Sense of Technology Trends in the Information Technology Landscape: A Design Science Approach. MIS Quarterly, 32(4), 779-809.

[3] Altay, N., and Green III, W. G. (2006). OR/MS research in disaster operations management. European Journal of Operational Research, 175(1), 475-493.

[4] Becerra-Fernandez, I., Xia, W., Gudi, A., and Rocha, J. (2008b). Task Characteristics, Knowledge Sharing and Integration, and Emergency Management Performance: Research Agenda and Challenges. Proceedings of the 5th International ISCRAM Conference - Washington, DC, USA.

[5] Bharosa, N., and Janssen, M. (2009). Reconsidering information management roles and capabilities in disaster response decision-making units. Proceedings of the 6th International ISCRAM Conference - Gothenburg, Sweden.

[6] Bo, J., Xiaxin, T., Ping, L., and Yanru, W. (2009). WebGIS Based Information and Decision-Making Support System for Earthquake Disaster Reduction: IEEE Computer Society.

[7] Bunge, M. (1967). Scientific research. 1, The search for system. Berlin; New York: Springer.

[8] Chen, R., Sharman, R., Rao, H. R., and Upadhyaya, S. (2008). An Exploration of Coordination in Emergency Response Management. Communications of the ACM, 5(51), $66-73$.

[9] Chen, R., Sharman, R., Rao, H., and Upadhyaya, S. (2007). Design principles for critical incident response systems. Information Systems and E-Business Management, 5(3), 201-227-227.

[10] Day, J. M., Junglas, I., and Silva, L. (2009). Information Flow Impediments in Disaster Relief Supply Chains. Journal of the Association for Information Systems, 10(8), 637-660.

[11] Dubin, R. (1978). Theory building. London: Free Press.

[12] Engelmann, H., and Fiedrich, F. (2007). Decision Support for the Members of an Emergency Operation Centre 
after an Earthquake. Proceedings of the 4th International ISCRAM Conference - Delft, The Netherlands.

[13] Federal Emergency Management Agency. FEMA: Learn About the Types of Disasters. Retrieved from http://www.fema.gov/hazard/types.shtm.

[14] Fruhling, A. N., and Vreede, G.-J. de. (2006). Field Experiences with eXtreme Programming: Developing an Emergency Response System. Journal of Management Information Systems, 22(4), 39-68.

[15] GAO. (2006). Disaster Relief: Governmentwide Framework Needed to Collect and Consolidate Information to Report on Billions in Federal Funding for the 2005 Gulf Coast Hurricanes: GAO-06-834.

[16] Gonzalez, R. A. (2009). Crisis response simulation combining discrete-event and agent-based modeling. Proceedings of the 6th International ISCRAM Conference Gothenburg, Sweden.

[17] Gregor, S. (2006). The Nature of Theory in Information Systems, 30(3), 611-642.

[18] Gregor, S. D., and Jones, D. (2007). The anatomy of a design theory. Journal of the Association for Information Systems, 8(5), 312.

[19] Gregor, S., and Hevner, A. R. (2011). Introduction to the special issue on design science. Information Systems and eBusiness Management, 9(1), 1-9.

[20] Hale, J. (1997). A layered communication architecture for the support of crisis response. Journal of Management Information Systems, 14(1), 235-255.

[21] Hall, D., Paradice, D., and Courtney, J. (2003). Building a Theoretical Foundation for a Learning-Oriented Management System. Journal of Information Technology Theory and Application, 5(2), 63-85.

[22] Hernandez, J. Z., and Serrano, J. M. (2001). Knowledgebased models for emergency management systems. Expert Systems with Applications, 20(2), 173-186.

[23] Hevner, A. R., March, S. T., Park, J., and Ram, S. (2004). Design Science in Information Systems Research. MIS Quarterly, 28(1), 75-105.

[24] Horan, T.A. and Schooley, B.L. (2007). Time-critical information services. Communications of the ACM, 50(3), 73-78.

[25] Housel, T.J., El Sawy, O.A., and Donovan, P.F. (1986). Information systems for crisis management: Lessons from Southern California Edison. MIS Quarterly, 10(4), 389-400.

[26] Hsieh, P.-H. (2004). A Data-Analytic Method for Forecasting Next Record Catastrophe Loss. Journal of Risk and Insurance, 71(2), 309-322.
[27] IFRC. Disaster management - IFRC. Retrieved from http://www.ifrc.org/en/what-we-do/disaster-management/.

[28] Iivari, J. (2007). A Paradigmatic Analysis of Information Systems As a Design Science. Scandinavian Journal of Information Systems, 19(2), 39-64.

[29] Jang, H.-C., Lien, Y.-N., and Tsai, T.-C. (2009). Rescue information system for earthquake disasters based on MANET emergency communication platform. Proceedings of the International Conference on Wireless Communications and Mobile Computing: Connecting the World Wirelessly, 623-627.

[30] Jianshe, D., Shuning, W., and Xiaoyin, Y. (1994). Computerized support systems for emergency decision making. Annals of Operations Research, 51, 315-325.

[31] Kuechler, B., and Vaishnavi, V. (2008). On theory development in design science research: anatomy of a research project. European Journal of Information Systems, 17(5), 489-504.

[32] Kwan, M.-P., and Lee, J. (2005). Emergency response after 9/11: the potential of real-time 3D GIS for quick emergency response in micro-spatial environments. Computers, Environment and Urban Systems, 29(2), 93-113.

[33] Lee, J., and Bui, T. (Eds.) 2000. A Template-Based Methodology for Disaster Management Information Systems. Proceedings of the 33rd Annual Hawaii International Conference on System Sciences, Vol. 1, Maui, Hawaii, IEEE Computer Society.

[34] Lorincz, K., Malan, D.J. , Fulford-Jones, T.R.F., Nawoj, A., Clavel, A., Shnayder, V. (2004). Sensor Networks for Emergency Response: Challenges and Opportunities. IEEE Pervasive Computing, pp. 16-23.

[35] March, S. T., and Smith, G. F. (1995). Design and natural science research on information technology. Decision Support Systems 15(4), 251-266.

[36] Markus, M. L., Majchrzak, A., and Gasser, L. (2002). A Design Theory for Systems That Support Emergent Knowledge Processes. MIS Quarterly, 26(3), 179-212.

[37] Mendonça, D., Rush, R., and Wallace, W. A. (2000). Timely knowledge elicitation from geographically separate, mobile experts during emergency response. Safety Science, 35(1-3), 193-208.

[38] Mendonça, D., Giampiero, B. E., and Wallace, W. A. (2001). Decision support for improvisation during emergency response operations. International Journal of Emergency Management, 1(1), 30-39.

[39] Nagel, E. (1942). The Structure of Science, Indianapolis, IN. Indianapolis, IN: Hackett Publishing Co.

[40] Nisha de Silva, F. (2001). Providing spatial decision support for evacuation planning: a challenge in integrating 
technologies. Disaster Prevention and Management, 10(1), 11-20.

[41] Nunamaker, J. F., Jr., Chen, M., and Purdin, T. D. M. (1990). Systems development in information systems research. Journal of Management Information Systems, 7(3), 89-106.

[42] Nunamaker, J.F., Jr, Weber, E. S., Smith, C. A. P., Chen, M. (1988). Crisis planning systems: tools for intelligent action. Proceedings of the Twenty-First Annual Hawaii International Conference on System Sciences, Vol. 3.

[43] Okada, C., Miyamoto, R., Yamane, A., Wada, T., Ohtsuki, K., and Okada, H. (Eds.) 2010. A Novel Urgent Communications Technologies for Sharing Evacuation Support Information in Panic-Type Disasters. Cancun, Mexico: IEEE Computer Society.

[44] Orlikowski, W. J., and Iacono, C. S. (2001). Desperately Seeking the 'IT' in IT Research. A Call to Theorizing the IT Artifact. Information Systems Research, 12(2), 121-134.

[45] Pavlou, P. A., and El Sawy, O. A. (2006). From IT Leveraging Competence to Competitive Advantage in Turbulent Environments: The Case of New Product Development. Information Systems Research, 17(3), 198227.

[46] Peffers, K., Tuunanen, T., Rothenberger, M. A., and Chatterjee, S. (2007). A Design Science Research Methodology for Information Systems Research. Journal of Management Information Systems, 24(3), 45-77.

[47] Perry, R. W. (2003). Incident management systems in disaster management. Disaster Prevention and Management, 12(5), 405-412.

[48] Pries-Heje, J., Baskerville, R., and Venable, J. (Eds.) 2008. Strategies for design science research evaluation. Proceedings of the European Conference on Information Systems. Galway, Ireland.

[49] Pries-Heje, J., and Baskerville, R. (2008). The Design Theory Nexus. MIS Quarterly, 32(4), 731-755.

[50] Reijers, H. A., Jansen-Vullers, M. H., Zur Muehlen, M., and Appl, W. Workflow management systems + swarm intelligence $=$ dynamic task assignment for emergency management applications. In Proceedings of the 5th International Conference on Business Process Management 2007, 125-140.

[51] Rolland, E., Patterson, R., Ward, K., and Dodin, B. (2010). Decision support for disaster management. Operations Management Research, 3(1), 68-79.
[52] Saleem, K., Luis, S., Deng, Y., Chen, S.-C., Hristidis, V., and Li, T. (2008). Towards a business continuity information network for rapid disaster recovery. Proceedings of the 2008 International Conference on Digital Government Research, 107-116.

[53] Sein, M.K., Henfridsson, O., Purao, S., Rossi, M., and Lindgren, R. (2011). Action Design Research. MIS Quarterly, 35(2), 37-56.

[54] Simard, A. J., and Eenigenburg, J. E. (1990). An Executive Information System to Support Wildfire Disaster Declarations. Interfaces, 20(6), 53-66.

[55] Simon, H. A. (1969). The science of the artificial. Cambridge: M.I.T. Press.

[56] Svensson, A., Holst, J., Lindquist, R., and Lindgren, G. (1996). Optimal Prediction of Catastrophes in autoregressive moving-average processes. Journal of Time Series Analysis, $17(5), 511-531$.

[57] Turoff, M., Chumer, M., van de Walle, B., and Yao, X. (2004). The Design of A Dynamic Emergency Response Management Information System (DERMIS). Journal of Information Technology Theory and Application 5.

[58] Turoff, M., Chumer, M., van de Walle, B., and Yao, X. (2003). The Design of a Dynamic Emergency Response Management Information System (DERMIS). Journal of Information Technology Theory and Application (JITTA) 5(4), 1-35.

[59] van Aken, J. E. (2004). Management Research Based on the Paradigm of the Design Sciences: The Quest for FieldTested and Grounded Technological Rules. Journal of Management Studies, 41(2), 219-246.

[60] van Santen, W., Jonker, C., and Wijngaards, N. (2009). Crisis Decision Making Through a Shared Integrative Negotiation Mental Model. Proceedings of the 6th International ISCRAM Conference - Gothenburg, Sweden.

[61] van Strien, P. J. (1997). Towards a Methodology of Psychological Practice. Theory \& Psychology, 7(5), 683700 .

[62] Walls, J. G., Widmeyer, G. R., and El Sawy, O. A. (1992). Building an Information System Design Theory for Vigilant EIS. Information Systems Research, 3(1), 36-59.

[63] Wex, F., Schryen, G., and Neumann, D. (2011). Intelligent Decision Support for Centralized Coordination during Emergency Response. Proceedings of the 8th International Conference on Information Systems for Crisis Response and Management (ISCRAM 2011), Lisbon, Portugal, May 8 - 11, 2011.

[64] Zimmermann, H.-J. (1996). Fuzzy set theory - and its applications, 3rd edition. Kluwer, Norwell, MA, USA. 